Article

\title{
First Record of Juncaceicola as Endophytic Fungi Associated with Deschampsia antarctica Desv.
}

\author{
Guilherme Afonso Kessler de Andrade ${ }^{1}$ (D), Ehidy Rocio Peña Cañón ${ }^{2}$ (i), \\ Rodrigo Paidano Alves ${ }^{1}$ (i), Daniela Schmitz ${ }^{3}$ (D), Adriano Luis Schünemann ${ }^{1}$ (i), \\ Margéli Pereira de Albuquerque ${ }^{1}$ (D), Jair Putzke ${ }^{1}$, Antônio Batista Pereira ${ }^{1, *(1)}$ and \\ Filipe de Carvalho Victoria ${ }^{1}$ (1) \\ 1 Núcleo de Estudos da Vegetação Antártica (NEVA), Universidade Federal do Pampa (UNIPAMPA), \\ Avenida Antônio Trilha, 1847, São Gabriel CEP 97300-000, Brazil; guilhermeafonsok@gmail.com(G.A.K.d.A.); \\ alvez_rdg@hotmail.com (R.P.A.); als@unipampa.edu.br (A.L.S.); \\ margeli_albuquerque@hotmail.com (M.P.d.A.); jairputzke@unipampa.edu.br (J.P.); \\ filipevictoria@unipampa.edu.br (F.d.C.V.) \\ 2 Grupo de Investigación Biología para la Conservación, Departamento de Biología, Universidad Pedagógica y \\ Tecnológica de Colombia, Avenida Central del Norte 39-115, Tunia 150003, Colombia; erociopc@hotmail.com \\ 3 Laboratório de Ecologia Evolutiva de Plantas (LEEP), Departamento de Biologia Vegetal, \\ Universidade Federal de Viçosa (UFV), Av. PH Rolfs, Viçosa CEP 36570-000, Brazil; \\ danni_schmitz@hotmail.com \\ * Correspondence: antoniopereira@unipampa.edu.br; Tel.: +55-(055)-3237-0858
}

Received: 13 April 2018; Accepted: 31 July 2018; Published: 27 September 2018

\begin{abstract}
In the current study, we present the molecular characterization of an endophyte fungus associated with the leaves of Deschampsia antarctica Desv. (Poaceae), a monocot species native to Antarctica. The isolate was obtained from 90 leaf fragments from two distinct collection sites, both located on Half Moon Island, South Shetland Islands and Maritime Antarctica. The internal transcribed spacer region (ITS) was sequenced and the endophytic fungus was identified as belonging to the genus Juncaceicola Tennakoon, Camporesi, Phook and K.D. Hyde (99\% nucleotide sequence identity). When compared to all fungi of the genus Juncaceicola deposited in data base, our isolate showed greater proximity with Juncaceicola typharum, however, because it presents a low bootstrap value to be considered a new species, we treat it as Juncaceicola cf. typharum. Moreover, the identification of our isolate as belonging to the genus Juncaceicola makes this the first occurrence of a species of this genus to be associated with the leaves of Antarctic plants. This work is considered as a starting point for other studies with fungi of this genus associated with leaves of Deschampsia antarctica, as it presents results from two collection points on a single Antarctic island, suggesting that new sites and new Antarctic islands should be explored.
\end{abstract}

Keywords: antarctic; mycodiversity; taxonomy; phylogeny; isolation; fungi

\section{Introduction}

Antarctica is one of the regions on the planet with extreme environment [1]. The establishment and survival of living organisms are limited by conditions such as low temperature and nutrient availability, strong winds, high sublimation and evaporation, frequent freezing-thawing cycles, low annual precipitation, high solar incidence and ultraviolet radiation, and low water availability [2-5]. In terms of biomass and taxonomic diversity, microorganisms such as bacteria and fungi comprise the dominant groups of most Antarctic ecosystems, because they respond to these conditions successfully [6].

Fungi are present in abundance in Antarctica [7], and the described filamentous fungi species belongs to the major groups in the Fungi Kingdom, such as Chytridiomycota, Zygomycota (a phylum no 
longer accepted in the new classification due to its polyphyletic nature), Glomeromycota, Ascomycota and Basidiomycota $[5,8,9]$. The distribution of fungi in Antarctica is related to the dispersal of different substrata such as soils [10], seawater [11] and plants [9]. Previous studies conducted by Rosa et al. [12,13], Santiago et al. [9] and Upson et al. [14] reported endophytic fungi isolated from Deschampsia antarctica Desv. (Poaceae).

The term 'endophyte' is used to refer to any organism that colonizes the internal tissues of plants and without causing apparent damage to the host [15]. After more than 200 years of research, endophytic fungi represent approximately $7 \%$ of the 1.5 million fungi estimated for Earth [16], and have been reported to be found in almost 300,000 terrestrial plant species. It is suggested that endophytic and mycorrhizal fungi are associated with most plants in natural ecosystems [15,17]. In order to increase the knowledge of diversity of endophyte fungi, plants that live in poorly explored habitats are being used as sources to discover new species [18].

To understand ecological functions and the impacts on plant communities, it is important to understand first how different types of fungi live in these places [19]. However, there is not yet a complete characterization of the microorganisms found in Antarctica, especially fungal communities [12].

Studies involving endophytic fungi have increased over the last 30 years; it has been observed that these fungi have important roles in plant development [20]. Because the high isolation rate of new endophytic fungi from plants living in under-exploited habitats such as Antarctica, researchers are using plant species from this location to discover new endophytic fungi and generate increased knowledge regarding their diversity and their capacity to produce new natural products with potential biological activity $[16,21]$.

The aim of the present study was to isolate and characterize, by molecular phylogeny and in vitro growing experiments, the endophytic fungus associated Deschampsia antarctica Desv. (Poaceae) collected from Half Moon Island, in order to deepen knowledge on the fungal diversity in Antarctic ice-free areas.

\section{Materials and Methods}

\subsection{Study Area and Sample Collection}

The samples were collected from Half Moon Island $\left(62^{\circ} 35^{\prime} 24^{\prime \prime}\right.$ S $59^{\circ} 54^{\prime} 36^{\prime \prime}$ W) in the South Shetland Islands, Antarctica. Specimens of $D$. antarctica were sampled randomly from two different sites (Hill Xenia: $62^{\circ} 35^{\prime} 03.26^{\prime \prime} \mathrm{S} 59^{\circ} 54^{\prime} 45.14^{\prime \prime} \mathrm{W}$ and Hill Gabriel: $62^{\circ} 35^{\prime} 15.49^{\prime \prime} \mathrm{S} 59^{\circ} 55^{\prime} 40.35^{\prime \prime} \mathrm{W}$ ), during the austral summer season in February and April of 2015 (Figure 1) in a total of five samples for each site. The sampled were stored in sterile plastic bags and transported in the freezer $\left(-20^{\circ} \mathrm{C}\right)$ to Brazil by members of the Antarctic Expedition of the Brazilian Antarctic Program.

\subsection{Isolation of the Endophytic Fungus}

The isolation method was conducted in the Núcleo de Estudos da Vegetação Antártica (NEVA), located at the Universidade Federal do Pampa (UNIPAMPA, São Gabriel-RS, Brazil). The Plastic bags containing $D$. antarctica were opened under a laminar flow cabbinet. Three healthy leaves per plant were selected for this study. The middle sections of each leaf were cut into three fragments (approximately $1 \mathrm{~cm}$ ) and were dipped in $70 \%$ ethanol $(1 \mathrm{~min})$ and $2 \%$ sodium hypochlorite ( $3 \mathrm{~min})$, followed by one wash with sterile distilled water $(2 \mathrm{~min})$, following the method of Rosa et al. [12]. The fragments were plated on Petri dishes $(90 \mathrm{~mm})$ containing potato dextrose agar (PDA; Sigma-Aldrich-70139, Merck KGaA Company, Darmstadt, Germany) supplemented with chloramphenicol $\left(100 \mu \mathrm{g} \mathrm{mL}^{-1}\right)$. The inoculated dishes were incubated at $18 \pm 1{ }^{\circ} \mathrm{C}$ in the absence of light to allow mycelia growth. After 60 days of incubation, the mycelial discs $(8 \mathrm{~mm})$ were prepared using the isolated culture, which served as source of inoculum. The mycelial discs were aseptically transferred into sterilized dishes containing PDA medium. The cultures were incubated at $20 \pm 1{ }^{\circ} \mathrm{C}$ 
in the absence of light. Isolated fungi were stored in distilled water [22] and later deposited in the Herbário Bruno Edgar Irgang at the Universidade Federal do Pampa, by the voucher HBEI 023.

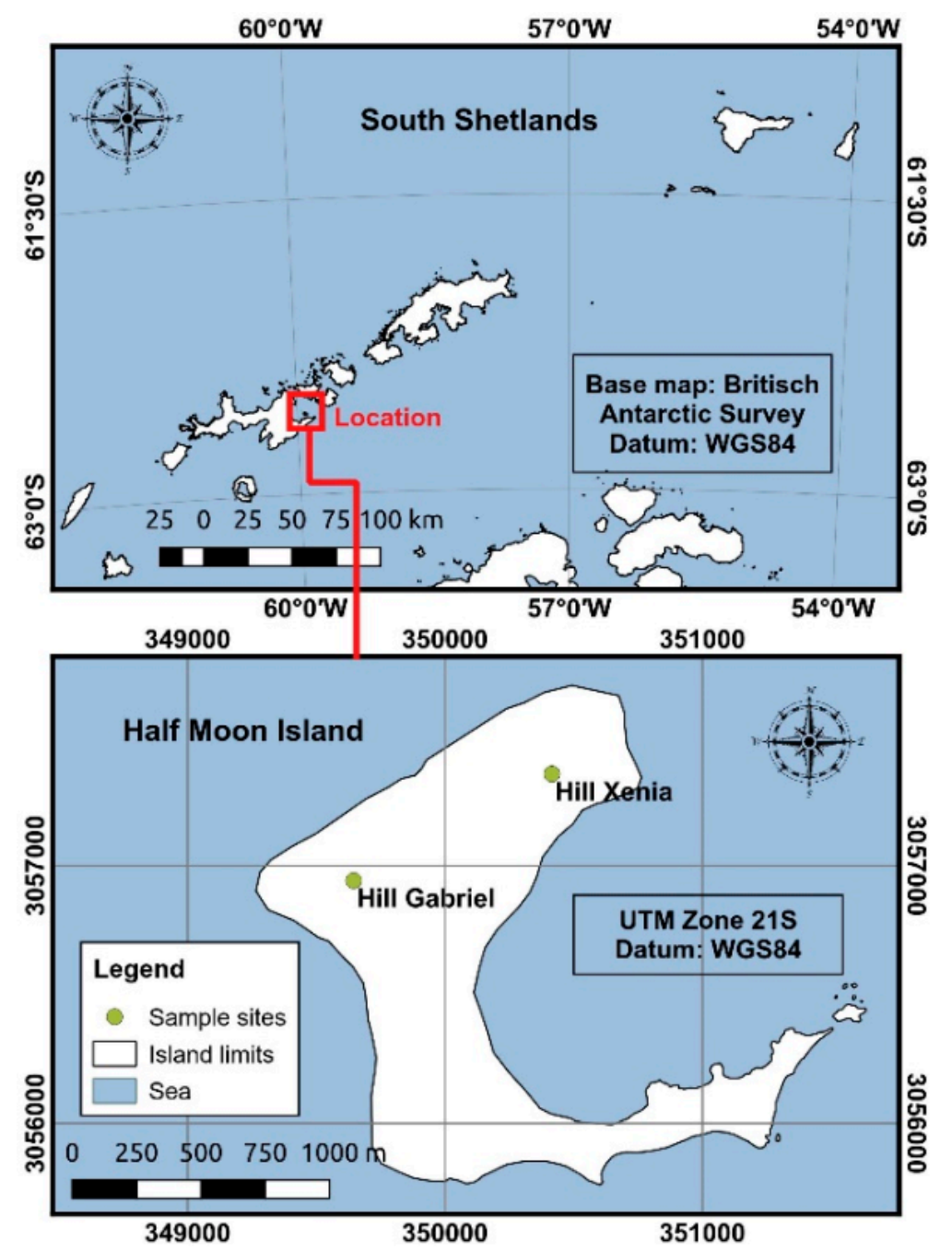

Figure 1. Location of Half Moon Island in the South Shetland archipelago in maritime Antarctica showing the sites where leaf samples of Deschampsia antarctica were collected (green dots).

\subsection{DNA Extraction, Amplification and Purification}

DNA extraction was performed using Norgen Plant/Fungi DNA isolation kit (Biotek Corporation, model 26200, Thorold, ON, Canada), the fungi were inoculated in BDA culture medium and extraction took place after the 7 th day of fungus inoculation. All the mycelium present in the plate was used, with a total $\leq 100 \mathrm{mg}$ for the extraction according to the protocol established by the kit. The internal transcribed spacer (ITS) region was amplified by polymerase chain reaction (PCR) using universal primers ITS1 (5_-TCCGTAGGTGAACCTGCGG-3_) and ITS4 (5_-TCCTCCGCTTATTGATATGC-3) described by White et al. [23]. Amplification of the ITS region was performed as follows: $95^{\circ} \mathrm{C}$ for $5 \mathrm{~min}$, followed by 40 cycles of $94{ }^{\circ} \mathrm{C}$ for $60 \mathrm{~s}, 50{ }^{\circ} \mathrm{C}$ for $60 \mathrm{~s}$, and $72{ }^{\circ} \mathrm{C}$ for $60 \mathrm{~s}$, with a final extension at $72{ }^{\circ} \mathrm{C}$ for 5 min [12]. The amplified DNA was cleaned using Wizard ${ }^{\circledR}$ SV Gel and PCR Clean-Up System (Promega, Fitchburg, WI, USA) according to the manufacturer's protocol. Sequencing was performed using an ABI Prism ${ }^{\circledR} 3500$ Genetic Analyzer (Applied Biosystems, Foster City, CA, USA). 


\subsection{Phylogenetic Analysis}

The sequence was corrected manually and edited using BioEdit v.7.2.5 software [24]. The edited sequence was checked using Chromas 2.6 software [25]. A consensus sequence was obtained using SeqMan software from DNASTAR [26]. The sequence data generated in this study have been submitted to GenBank and provided with the accession number MG272499. To achieve identification of species classification based on the ITS region, the consensus sequence was aligned with sequences from the Phaeosphaeriaceae family that had Query Cover greater than $70 \%$ and Identity greater than $85 \%$ as retrieved from the NCBI GenBank database using the BLAST tool [27]. For each alignment obtained for the present analysis a pairwise distance matrix (distance p) were obtained in order to evaluate the genetic distance for our new sequence with others from public database.

A phylogenetic tree was obtained by using the Maximum Likelihood method based on the General Time Reversible nucleotide model [28] with 1000 bootstrap replications according to Felsenstein [29] and performed with the program MEGA version 7.0 [30]. The best model for nucleotide substitution was established using MEGA 7.0 and adjusted in JModelTest [31]. The information regarding fungal classification followed MycoBank (http:/ / www.mycobank.org) and the Index Fungorum (http:// www.indexfungorum.org) $[8,32,33]$.

\subsection{Effects of Temperature on Mycelia Growth}

To determine the optimal growth temperature, the fungus was inoculated at 3 different temperatures $\left(15^{\circ} \mathrm{C}, 20^{\circ} \mathrm{C}\right.$ and $\left.25^{\circ} \mathrm{C}\right)$ in PDA medium. Fifteen replicates were used for each treatment. $8 \mathrm{~mm}$ discs containing active mycelium were placed in the center of the Petri dish and maintained in photoperiod cameras. Mycelial growth was measured with a pachymeter by the back of the dishes in diameters every $72 \mathrm{~h}$ in 8 directions for 21 days in total.

Two comparisons were made for statistical analysis of growth data at different temperatures. For the first comparison the sum of the radial growth averages in the 7 days of measurement was made comparing the three different temperatures. For the second comparison the growth averages were performed for the fifteen replicates per temperature per day. For both cases the normality tests of Shapiro-Wilk [34] were performed. When the sample was shown to be from a non-normal population, the non-parametric Mann-Whitney U Test [35] was used. In samples with normal distribution population, Analysis of variance (ANOVA) and Tukey test [36] at 5\% were used to compare the growth at the three temperatures. It was decided not to perform the treatment for the presence of outlier in the sampled sets.

\subsection{Morphological Description}

Morphological characterization was performed according to Noble [37], using PDA culture medium at $20{ }^{\circ} \mathrm{C}$. Macroscopic structures were analyzed for der texture. For mycelial color using The Online Auction Color Chart [38], growth diameter, mycelia growth type and microscopic structures, the type of hyphae, size of hyphae, presence of connection clips and other structures were evaluated.

\section{Results}

In this study, we present preliminary outcomes for occurrence of the genus Juncaceicola in the Antarctic continent, where ten individual samples of $D$. antarctica were obtained from two distinct sites ( 5 samples per site) of Half Moon Island, a single isolated from endophytic fungus was recovered from 90-leaf fragments. We present here the molecular identification, preliminary morphological description and growth behavior related to temperature variation, as below.

\subsection{Phylogenetic Analyzes}

The ITS1-ITS4 rDNA phylogeny demonstrated that our isolated fungus probably belongs to the genus Juncaceicola Tennakoon, Camporesi, Phookamsak and K.D. Hyde [39]. Our sequence was aligned 
with 36 other sequences selected from the best GenBank BLAST results and the phylogenetic analysis of the isolate UNIPAMPA_ROSA, showed a close relationship with the Juncaceicola genus, supported by a higher bootstrap value (99), when compared with ITS homologues from other genera obtained from GenBank. The Maximum Likelihood (ML) consensus tree, which is most consistent in topology, are show in Figure 2. The genetic distances obtained in comparison to our sequence and the other homologous regions of the ITS used for this study corroborate the hypothesis that our sequence is probably of a species of the genus Juncaceicola (Supplementary Figure S1).

The genera Phaeosphaeriopsis and Populocrescentia had 19\% ITS sequence identity with Juncaceicola. According to BLAST comparisons of the ITS regions, the sequences that presented closest query coverage and identity values were five species (J. dactylidis, J. oreochloae, J. padellana, J. alpina and J. achilleae) belonging to the same genus. J. achilleae (KX449525) and J. alpina (NR145172) obtained cover of $100 \%$ and identity of $97 \%$ to the query.

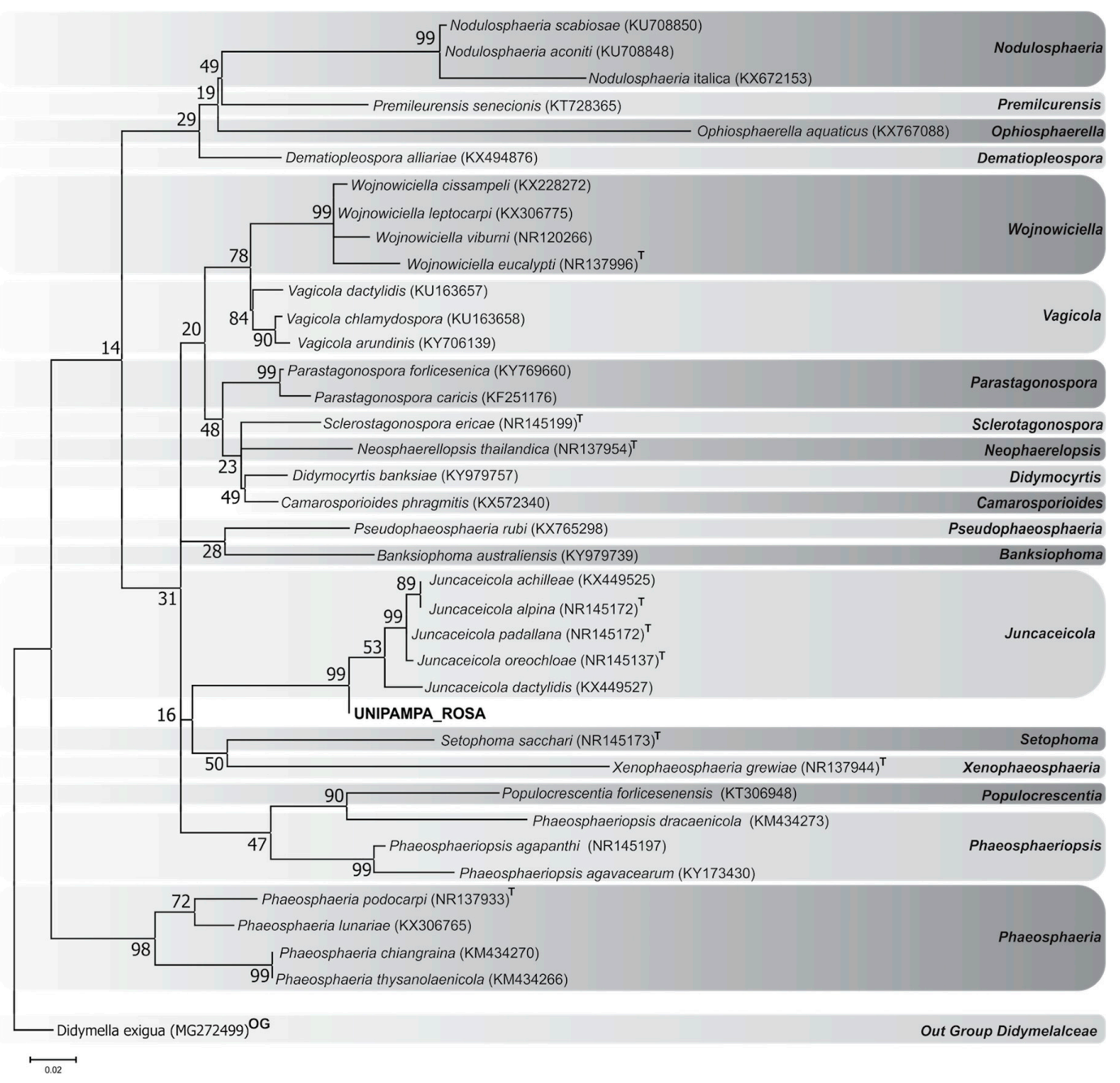

Figure 2. Maximum Likelihood (ML) consensus tree showing the relationship among Deschampsia antarctica endophytic fungi (UNIPAMPA_ROSA) and other fungal sequences belonging to the Phaeosphaeriaceae family, following BLAST analysis. The tree was constructed using GenBank data based on rDNA (ITS1-ITS4) fragment sequence using MEGA version 7 with a maximum likelihood method (bootstrap values are shown at nodes). The tree is rooted to Didymella exigua (CBS 183.55). The sequences of type species are indicated as superscript $\mathrm{T}$.

In addition, phylogenetic analysis was performed for all species belonging to the genus Juncaceicola and our isolate (Figure 3). The analysis was composed of five sequences from previous analyses 
(J. dactylidis, J. oreochloae, J. padellana, J. alpina and J. achilleae), and three more species were reported to MycoBank and Index Fungorum, J. Italic (KX500110), J. luzulae (KX449629) and J. typharum (KF251192), using the GenBank database [39,40]. The phylogenetic analyses show a lower identity of ITS sequences from our isolate within other Juncaceicola sequences available. The genetic distances obtained from the pairwise distance matrix also do not allow us to determine that our species has sufficient similarity with the other species of Juncaceicola already described (Supplementary Figure S2). Our isolate grouped closer to J. typharum when compared to seven other fungal species; however, the lower bootstrap support is insufficient to consider our sample as belonging to this species, so we treated it as Juncaceicola cf. typharum, because, we do not have sufficient data, such morphological and molecular features to definitively determine this hypothesis of identification.

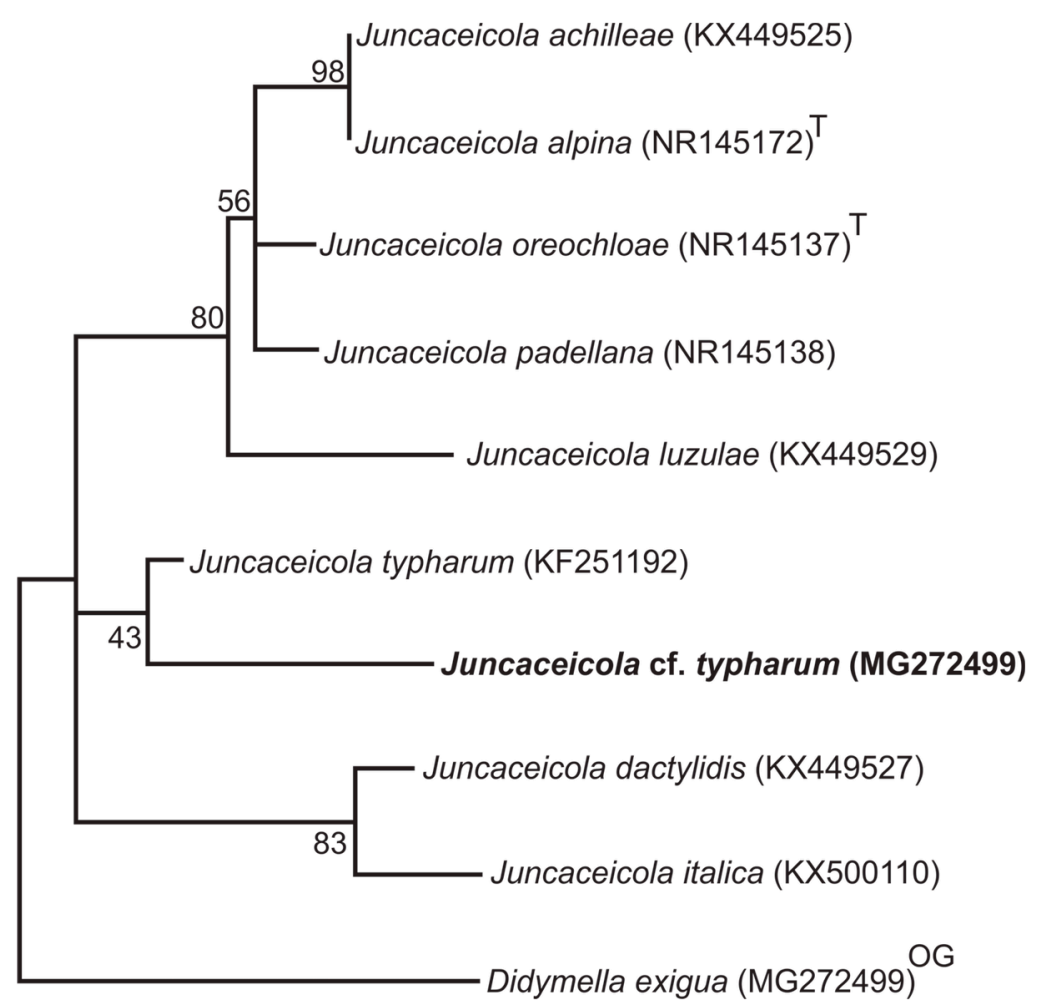

Figure 3. ML bootstrap tree showing the relationship among Deschampsia antarctica endophytic fungus (Juncaceicola cf. typharum) and other fungal sequences belonging to the Juncaceicola genus, following BLAST analysis. The tree was constructed using GenBank data based on rDNA (ITS1-ITS4) fragment sequence using MEGA program version 7 with a maximum likelihood method (bootstrap values are shown at nodes). The tree is rooted to Didymella exigua (CBS 183.55). The sequences of type species are indicated as superscript $\mathrm{T}$.

\subsection{Morphological Description}

Culture characteristics: PDA colonies showing slow growth in PDA reaching 34-56 mm in diameter after 4 weeks at $20^{\circ} \mathrm{C}$, cotonous, in some cases the mycelium reaching almost the same height of the original transplant disc, zoned by different heights and margin irregular. Colony with aged light pink color (OAC606) in the center, along the colony and at the edge of the plate varying between darker aged rose (OAC603) or light pink (OAC599), end of colony with hyaline hyphae. Reverse showing the same coloration in the center (OAC606), and also the same variation in the course of the colony (OAC603-OAC599) and the end of the colony with hyaline hyphae.

Microscopic: Hyphas with 1.5-2 $\mu \mathrm{m}$ diameter, arranged in bundles, hyaline, smooth, septate (septa per $100 \mu \mathrm{m}$ at least), with inconspicuous septa, not very visible, flexuous, sterile, presence of 
intercalary and terminal chlamydospores, irregular (ranging from nailed to catenulate), hyaline, with an internal oily reflux guttula (5 $\mu \mathrm{m}$ to $10 \mu \mathrm{m}$ in diameter), usually arranged in clusters, forming a compact structure only of chlamydospores, presence of nematophagous loops (Figure 4).

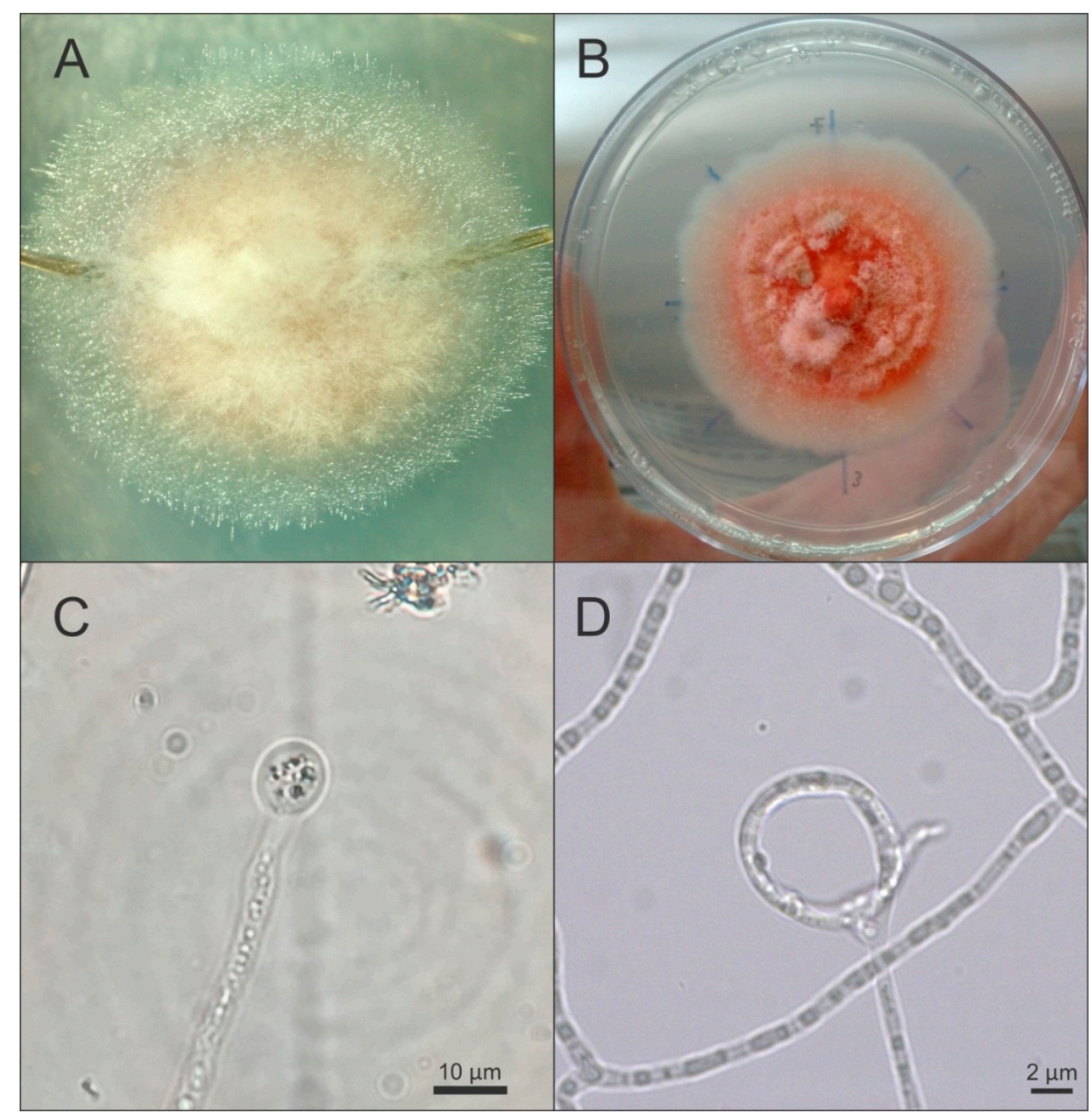

Figure 4. Juncaceiola cf. typharum. (A) Isolation of the fungus through a fragment of D. antarctica. (B) Isolated culture of Juncaceiola cf. typharum. (C) Chlamydospore. (D) Nematode ring. Scale bars: $\mathrm{C}=10 \mu \mathrm{m}, \mathrm{D}=2 \mu \mathrm{m}$.

\subsection{Effects of Temperature on Mycelia Growth}

It can be seen in Figure 5 that our isolate showed a small growth at $15^{\circ} \mathrm{C}$ and that the average growth was decreasing as the days went by. On the other hand, we noticed that the isolate showed a better growth in the temperatures of $20^{\circ} \mathrm{C}$ and $25^{\circ} \mathrm{C}$, and that, for the most part, presented an increasing curve of mycelial growth in these conditions in the course of the days.

We verified the best growth of the temperatures of $20^{\circ} \mathrm{C}$ and $25^{\circ} \mathrm{C}$ by means of statistical tests, we used the means of the daily replicas and using the Tukey test. It was observed that the temperatures of $20^{\circ} \mathrm{C}$ and $25^{\circ} \mathrm{C}$ did not present significant differences in relation to the growth when compared between them, however, these temperatures showed a significant difference when compared to the temperature increase of $15^{\circ} \mathrm{C}$ (Figure 5). The Man Whitney U Test showed that the sum of the averages of the growth in the 7 days differ statistically among treatments ( $p$-value always below $3.24 \times 10^{-6}$ ). 


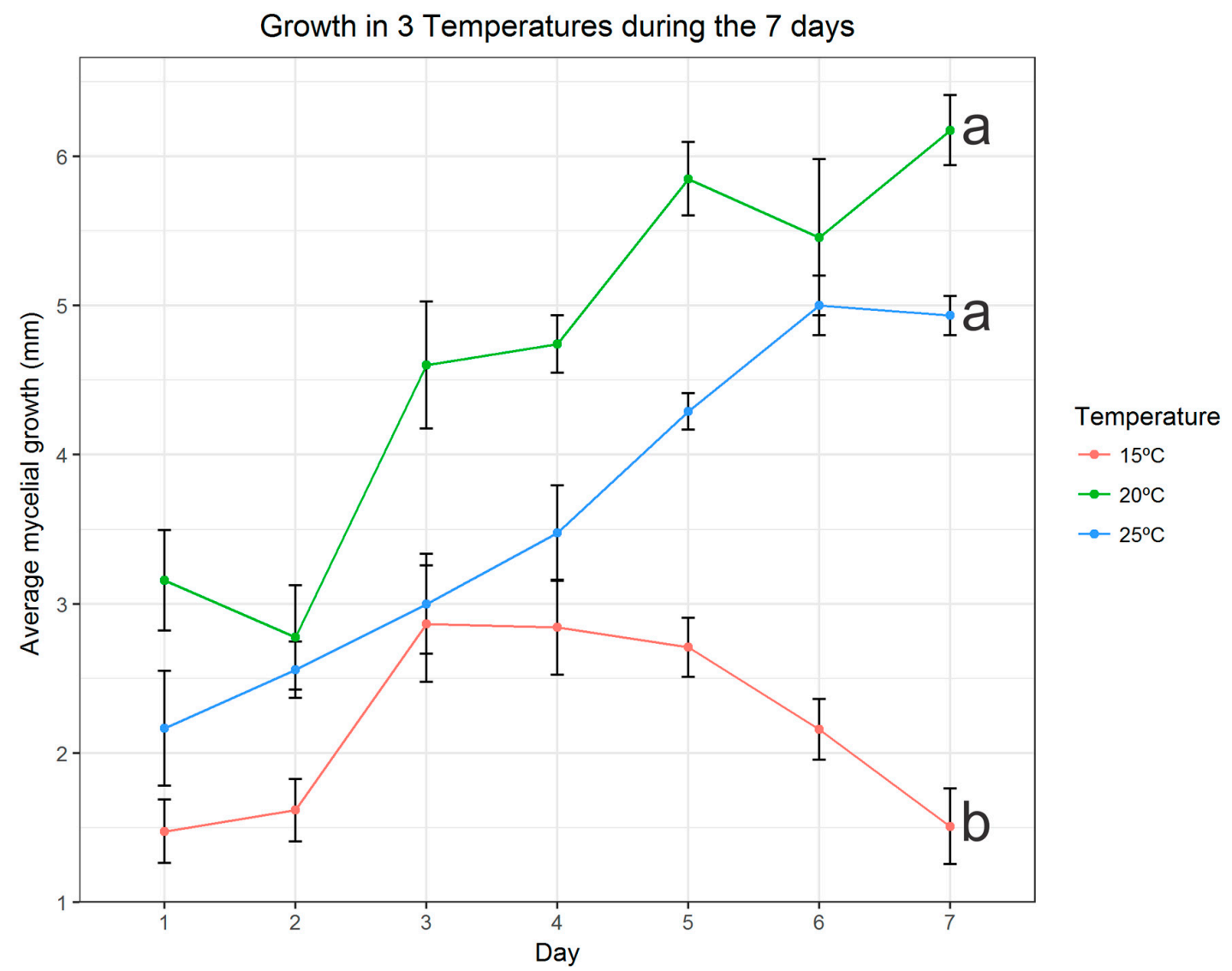

Figure 5. Average mycelial growth in mm during the 7 days of measurement at the 3 different temperatures. The graphic was built using specific packages in the R studio software. Temperatures followed by the same letter do not differ in the Tukey test at $5 \%$.

\section{Discussion}

Endophytic fungi belonging to Phaeosphaeriaceae have previously been recovered from monocots and dicots in Antarctic ecosystems $[9,12,13]$. The species of this family are widely distributed among plants as pathogens or as saprobes [39]. Currently, eight species are grouped under the genus Juncaceicola, which were collected from Asteraceae, Juncaceae, Poaceae and Typhaceae. In the present evaluation, the isolate was closely related to J. typharum. This species is reported from Typhaceae (Typha angustifolia L., Typha australis L. and Typha latifolia L.) and Poaceae (Spartina alterniflora Loisel, and Spartina patens (Aiton) Muhl). J. alpina is the only species related to the genus Deschampsia P. Beauv., such as Deschampsia caespitosa (L.) P. Beauv and Deschampsia flexuosa (L.) Trin, but none of these grass species occurs in Antarctica [9,39].

Therefore, species of the genus Juncaceicola have not yet been discovered in the Antarctic continent, whereas species of the genus Phaeosphaeria have been found as endophytes of D. antarctica and C. quitensis on the ice-free areas of the South Shetlands archipelago [12,13]. According to Rosa et al. [12], the genera Alternaria and Phaeosphaeria are the most abundant in the leaves of D. antarctica. Thus, our results suggest the first identification of this genus in the Antarctic region.

Our study is a starting point for the work with isolates of the genus Juncaceicola in the Antarctic continent, seeking to fill the shortage of knowledge of the ecological function of the fungi of this genus in the Antarctic environment. Therefore, further studies should be performed to understand the relation of fungi of this genus with the Antarctic hairgrass species (Deschampsia antarctica). Since the relationship between the fungus and the plant may be specific, where the fungus is host of only one species of plant or a certain group of plants, and in these cases, the fungus does not relate to other 
plants in the same habitat of your host plant [41]. According to Ruisi et al. [5], Antarctica is a potential place to find endemic and new fungal species, which will be important in turn to understand fungal diversity and ecology [12,42]. Intensive research for new and more effective species of endophyte fungi with biotechnology relevance is underway and this includes the search for new ecological niches, such as Antarctica, for new potential sources [43,44].

The macroscopic character of differentiation of fungi species of the genus Juncaceicola is the ascomata and ascospores [39,40], but Juncaceiola cf. typharum did not present the formation of reproductive structures in culture medium, and we did not obtain this information. Our isolate shows slower mycelial growth when compared to the growth of other Juncaceicola species already reported $[39,40]$. The coloration of the colonies of the species already described of this genus varied between white, cream, yellowish, brown, brown, gray and black $[39,40]$, however, our isolate presents a different coloration, dark pink tones to clear. The phylogenetical and the pairwise distance matrix analysis allows us to only suggest that our species is hypothetically a new species of Juncaceicola, since the genetic distances obtained demonstrate that our sequence is to dissimilar the other species already described and with sequences available in Genbank. The phylogenetic analysis approximates our species of Juncaceicola typharum, but without sufficient morphological characteristics we do not have any other information that can be compared with its original description. Although sequences of nuclear ribosomal spacers are widely used for phylogenetic analysis, we must always be careful to avoid over interpretation, since sequences such as ITs can be misleading when incorporated into phylogenies, since these regions are involved in a lower rate in fungi and can be present in many copies in the plant genome [45]. Taking into account that our sample is an endophyte fungus obtained from leaves of an Antarctic plant, selection pressure is higher in the organism living there [46], and the molecular relationships between endophyte fungi and their hosts have not yet been fully established [47], further analyzes are necessary for the taxonomic determination of our new fungi species.

Putzke and Pereira [48] described Phaeosphaeria deschampsii, a new species of Deschampsia antarctica parasite for Half Moon Island. These authors [48] also claim that plant pathogenic fungi are few known to the Antarctic region and that climate change can cause pathogens restricted to some areas to be found in new locations.

Despite being related as an endophyte, our isolate showed a strong grouping with fungi of the genus Juncaceiola, a genus of 8 fungal species that are reported as parasites of plant species, including species of the family Poaceae $[39,40]$.

Working with fungi isolated from Antarctic soils, report that most of the isolated fungi grow at all tested temperatures, however, in the majority, they had their best growth in temperatures close to $20^{\circ} \mathrm{C}$ and $25^{\circ} \mathrm{C}$ [49]. As well as, isolated fungi of mosses presented, for the most part, better growth between 15 and $24{ }^{\circ} \mathrm{C}$ [50]. However, we did not find data on fungal growth associated with Antarctic grasses. The occurrence of new species of plant parasitic fungi in Antarctica may be related to climate change in this region because some fungi, such as our isolate, have better growth rates at higher temperatures.

\section{Conclusions}

Our results served as a starting point for studies with this isolate, further studies with this isolate need to be performed for a better implementation, as well as, work with more sampling points in different Antarctic islands should be done to verify the occurrence of this isolate in the other ice-free areas of Antarctica. The identification of our isolate was not conclusive at species level, because through our morphological characterization we did not obtain enough data well-based taxonomic analysis. Through the temperature test it was possible to observe that, like other fungi already reported for Antarctica, our fungus has better growth at higher temperatures rates, such between $20^{\circ} \mathrm{C}$ and $25^{\circ} \mathrm{C}$. The isolate showed low identity of the ITS sequences for sequences of fungal species belong to the genus Juncaceicola. Our isolate was closer to Juncaceicola typharum, however, the data obtained up to date are not conclusive to suggest that this fungus could really be a new species. Therefore, we suggest that our isolate be identified as Juncaceicola cf. typharum. More taxonomic studies, such as 
multigenic phylogeny with the combination of regions such as ITS + LSU + SSU, as performed by Tennakoon et al. [39], are necessary to identify the fungal endophyte of Deschampsia antarctica obtained in our study.

Supplementary Materials: The following are available online at http://www.mdpi.com/1424-2818/10/4/ 107/s1, Figure S1: Estimates of Evolutionary Divergence between sequences analyzed in the phylogeny. Figure S2: Estimates of Evolutionary Divergence between sequences from Deschampsia antarctica endophytic fungus (Juncaceicola cf. typharum) and other fungal sequences belonging to the Juncaceicola genus, following BLAST analysis.

Author Contributions: G.A.K.d.A., E.R.P.C., R.P.A., D.S., A.L.S. and F.d.C.V. conceived and designed all experiments. G.A.K.d.A. and R.P.A. performed DNA extration and the in vitro growth experiments. G.A.K.d.A., E.R.P.C., A.L.S., M.P.d.A., J.P. and A.B.P. carried out the morphological analysis and validate thus with help of statistical methods mentioned in the methodology section. G.A.K.d.A., E.R.P.C and F.d.C.V. analyzed the phylogenetic data, including the alignment and phylograms obtained. A.L.S., M.P.d.A., J.P., A.B.P. and F.d.C.V. contributed with materials and resources. G.A.K.d.A., R.P.A., F.d.C.V. wrote the paper with assistance from other authors. All authors reviewed and approved the final version of the paper.

Funding: This work integrates the National Institute of Science and Technology Antarctic Environmental Research (INCT-APA) which receives scientific and financial support from the National Council for Research and Development (CNPq processes: $n^{\circ}$ 574018/2008-5 and n $\left.{ }^{\circ} 446234 / 2015-0\right)$, Carlos Chagas Research Support Foundation of the State of Rio de Janeiro (FAPERJ n ${ }^{\circ}$ E-16/170.023/2008) and Research Support Foundation of the State of Rio Grande do Sul (FAPERGS).

Acknowledgments: This work had the support of the Coordenação de Aperfeiçoamento de Pessoal de Nível Superior-CAPES, the Conselho Nacional de Desenvolvimento Científico-CNPq, with the assignment of scholarships for G.A.K.d.A., E.R.P.C. and R.P.A. All authors thank these development agencies, as well the Universidade Federal do Pampa for the support provided in the development of this work. The authors also acknowledge the support of the Brazilian Ministries of Science, Technology and Innovation (MCTI), of Environment (MMA) and Inter-Ministry Commission for Sea Resources (CIRM) for the research support at Antartica. In addition, the authors gratefully acknowledge the reviewers and editors who attended this work, as we recognize how it became more qualified due to the suggestions received by all these parties. Finally, the authors thank the other members of Núcleo de Estudos da Vegetação Antártica (NEVA) for the unconditional support of the researches developed in our department.

Conflicts of Interest: The authors declare no conflict of interest.

\section{References}

1. Torres-Díaz, C.; Gallardo-Cerda, J.; Lavin, P.; Oses, R.; Carrasco-Urra, F.; Atala, C.; Acuña-Rodríguez, I.S.; Convey, P.; Molina-Montenegro, M.A. Biological Interactions and Simulated Climate Change Modulates the Ecophysiological Performance of Colobanthus quitensis in the Antarctic Ecosystem. PLoS ONE 2016, 11. [CrossRef] [PubMed]

2. Chénard, C.; Lauro, F.M. (Eds.) Microbial Ecology of Extreme Environments; Springer International Publishing: Cham, Switzerland, 2017.

3. Convey, P. Antarctic terrestrial biodiversity in a changing world. Polar Biol. 2011, 34, 1629-1641. [CrossRef]

4. Marcías, M.L.; Deregibus, D.; Saravia, L.A.; Campana, G.L.; Quartino, M.L. Life between tides: Spatial and temporal variations of an intertidal macroalgal community at Potter Peninsula, South Shetland Islands, Antarctica. Estuar. Coast. Shelf Sci. 2017, 187, 193-203. [CrossRef]

5. Ruisi, S.; Barreca, D.; Selbmann, L.; Zucconi, L.; Onofri, S. Fungi in Antarctica. Rev. Environ. Sci. Biotechnol. 2007, 6, 127-141. [CrossRef]

6. Franco, D.C.; Signori, C.N.; Duarte, R.T.D.; Nakayama, C.R.; Campos, L.S.; Pellizari, V.H. High Prevalence of Gammaproteobacteria in the Sediments of Admiralty Bay and North Bransfield Basin, Northwestern Antarctic Peninsula. Front. Microbiol. 2017, 8. [CrossRef] [PubMed]

7. Makhalanyane, T.P.; Van Goethem, M.W.; Cowan, D.A. Microbial diversity and functional capacity in polar soils. Curr. Opin. Biotechnol. 2016, 38, 159-166. [CrossRef] [PubMed]

8. De Menezes, G.C.A.; Godinho, V.M.; Porto, B.A.; Gonçalves, V.N.; Rosa, L.H. Antarctomyces pellizariae sp. nov., a new, endemic, blue, snow resident psychrophilic ascomycete fungus from Antarctica. Extremophiles 2017, 21, 259-269. [CrossRef] [PubMed]

9. Santiago, I.F.; Rosa, C.A.; Rosa, L.H. Endophytic symbiont yeasts associated with the Antarctic angiosperms Deschampsia antarctica and Colobanthus quitensis. Polar Biol. 2017, 40, 177-183. [CrossRef] 
10. Ding, Z.; Li, L.; Che, Q.; Li, D.; Gu, Q.; Zhu, T. Richness and bioactivity of culturable soil fungi from the Fildes Peninsula, Antarctica. Extremophiles 2016, 20, 425-435. [CrossRef] [PubMed]

11. Gonçalves, V.N.; Vitoreli, G.A.; de Menezes, G.C.A.; Mendes, C.R.B.; Secchi, E.R.; Rosa, C.A.; Rosa, L.H. Taxonomy, phylogeny and ecology of cultivable fungi present in seawater gradients across the Northern Antarctica Peninsula. Extremophiles 2017. [CrossRef] [PubMed]

12. Rosa, L.H.; Vaz, A.B.M.; Caligiorne, R.B.; Campolina, S.; Rosa, C.A. Endophytic fungi associated with the Antarctic grass Deschampsia antarctica Desv. (Poaceae). Polar Biol. 2009, 32, 161-167. [CrossRef]

13. Rosa, L.H.; de Almeida Vieira, M.L.; Santiago, I.F.; Rosa, C.A. Endophytic fungi community associated with the dicotyledonous plant Colobanthus quitensis (Kunth) Bartl. (Caryophyllaceae) in Antarctica: Endophytic fungi associated with Colobanthus quitensis. FEMS Microbiol. Ecol. 2010. [CrossRef] [PubMed]

14. Upson, R.; Newsham, K.; Read, D. Root-fungal associations of Colobanthus quitensis and Deschampsia antarctica in the maritime and subantarctic. Arct. Antarct. Alp. Res. 2008, 40, 592-599. [CrossRef]

15. Khiralla, A.; Spina, R.; Yagi, S.; Mohamed, I.; Laurain-Mattar, D. Endophytic Fungi: Occurrence, Classification, Function and Natural Products. Endophytic Fungi Diversity Characterization and Biocontrol; Hughes, E., Ed.; Nova Science Publishers: New York, NY, USA, 2017; pp. 14-39, ISBN 978-1-53610-341-0.

16. Chowdhary, K.; Kaushik, N. Fungal endophyte diversity and bioactivity in the Indian medicinal plant Ocimum sanctum Linn. PLoS ONE 2015, 10, e0141444. [CrossRef] [PubMed]

17. Arnold, A.E. Endophytic Fungi: Hidden Components of Tropical Community Ecology. Tropical Forest Community Ecology; Carson, W., Schnitzer, S., Eds.; Wiley-Blackwell: Hoboken, NJ, USA, 2008; pp. 178-188, ISBN 978-1-405-11897-2.

18. Hokama, Y.; Savi, D.; Assad, B.; Aluizio, R.; Gomes-Figueiredo, J.; Adamoski, D. Endophytic Fungi Isolated from Vochysia divergens in the Pantanal, Matogrosso do sul: Diversity, Phylogeny and Biocontrol of Phyllosticta citricarpa. In Endophytic Fungi: Diversity Characterization and Biocontrol; Hughes, E., Ed.; Nova Science Publishers: New York, NY, USA, 2017; pp. 1-25, ISBN 978-1-53610-341-0.

19. Martin, F.; Cullen, D.; Hibbett, D.; Pisabarro, A.; Spatafora, J.W.; Baker, S.E.; Grigoriev, I.V. Sequencing the fungal tree of life. New Phytol. 2011, 190, 818-821. [CrossRef] [PubMed]

20. Araújo, W.L.; Lacava, P.T.; Marco, J.; Lima, A.O.S.; Sobral, J.K.; Azevedo, J.L.; Pizzirani-Kleiner, A.A. Isolamento de Microrganismos Endofíticos. Guiaprático: Isolamento e Caracterização de Microrganismos Endofíticos. Guia Prático: Isolamento e Caracterização de Microrganismos Endofíticos; Luiz de Queiroz: Piracicaba, Brasil, 2010; p. 167.

21. Strobel, G.; Daisy, B. Bioprospecting for microbial endophytes and their natural products. Microbiol. Mol. Biol. Rev. 2003, 67, 491-502. [CrossRef] [PubMed]

22. Castellani, A. Maintenance and cultivation of common pathogenic fungi of man in sterile distilled water. Further researches. J. Trop. Med. Hyg. 1967, 70, 181.

23. White, T.J.; Bruns, T.D.; Lee, S.B. Amplification and Direct Sequencing of Fungal Ribosomal RNA Genes for Phylogenetics. In PCR Protocols: A Guide to Methods and Applications; Innis, M.A., Gelfand, D.H., Sninsky, J.J., White, T.J., Eds.; Academic Press: San Diego, CA, USA, 1990; pp. 315-322, ISBN 0123721814.

24. Hall, T.A. BioEdit: A User-Friendly Biological Sequence Alignment Editor and Analysis Program for Windows 95/98/NT. In Nucleic acids Symposium Series; Information Retrieval Ltd.: London, UK, 1999; pp. 95-98.

25. Goodstadt, L.; Ponting, C.P. CHROMA: Consensus-based colouring of multiple alignments for publication. Bioinformatics 2001, 17, 845-846. [CrossRef] [PubMed]

26. Burland, T.G. DNASTAR's Lasergene sequence analysis software. Bioinform. Methods Protoc. 2000, 71-91. [CrossRef]

27. Altschul, S.F.; Madden, T.L.; Schäffer, A.A.; Zhang, J.; Zhang, Z.; Miller, W.; Lipman, D.J. Gapped BLAST and PSI-BLAST: A new generation of protein database search programs. Nucleic Acids Res. 1997, 25, 3389-3402. [CrossRef] [PubMed]

28. Nei, M.; Kumar, S. Molecular Evolution and Phylogenetics; Oxford University Press: Oxford, UK, 2000; ISBN 9780195135855.

29. Felsenstein, J. Confidence limits on phylogenies: An approach using the bootstrap. Evolution 1985, 39, 783-791. [CrossRef] [PubMed]

30. Kumar, S.; Stecher, G.; Tamura, K. MEGA7: Molecular Evolutionary Genetics Analysis version 7.0 for bigger datasets. Mol. Biol. Evol. 2016, 33, 1870-1874. [CrossRef] [PubMed] 
31. Posada, D. jModelTest: Phylogenetic model averaging. Mol Biolevol. 2008, 25, 1253-1256. [CrossRef] [PubMed]

32. MycoBank. Available online: http:/ / www.mycobank.org (accessed on 10 November 2017).

33. Index Fungorum. Available online: http:/ / www.indexfungorum.org (accessed on 10 November 2017).

34. Royston, P. Remark AS R94: A remark on Algorithm AS 181: The W test for normality. Appl. Stat. 1995, 44, 547-551. [CrossRef]

35. Hollander, M.; Douglas, A. Wolfe, Nonparametric Statistical Methods; John Wiley \& Sons: New York, NY, USA, 1999; pp. 68-75.

36. Chambers, J.M.; Freeny, A.; Heiberger, R.M. Analysis of Variance; Designed Experiments; Chapter 5 of Statistical Models; Chambers, J.M., Hastie, T.J., Eds.; Wadsworth \& Brooks/Cole: New York, NY, USA, 1992.

37. Nobles, M.K. Identification of cultures of Wood in habiting hymenomycetes. Can. J. Bot. 1965, 43, 1097-1139. [CrossRef]

38. OACC: The Online Auction Colour Chart: The New Language of Colour for Buyers and Sellers; OACC: Palo Alto, CA, USA, 2004; p. 12.

39. Tennakoon, D.S.; Hyde, K.D.; Phookamsak, R.; Wanasinghe, D.N.; Camporesi, E.; Promputtha, I. Taxonomy and Phylogeny of Juncaceicola gen. nov. (Phaeosphaeriaceae, Pleosporinae, Pleosporales). Cryptogam. Mycol. 2016, 37, 135-156. [CrossRef]

40. Hyde, K.D.; Hongsanan, S.; Jeewon, R.; Bhat, D.J.; McKenzie, E.H.C.; Jones, E.B.G.; Phookamsak, R.; Ariyawansa, H.A.; Boonmee, S.; Zhao, Q.; et al. Fungal diversity notes 367-490: Taxonomic and phylogenetic contributions to fungal taxa. Fungal Divers. 2016, 80, 1-270. [CrossRef]

41. Hughes, E. (Ed.) Endophytic Fungi: Diversity, Characterization and Biocontrol; Nova Publishers: New York, NY, USA, 2017; pp. 14-39, ISBN 978-1-53610-341-0.

42. Higgins, K.L.; Arnold, A.E.; Miadlikowska, J.; Sarvate, S.D.; Lutzoni, F. Phylogenetic relationships, host affinity, and geographic structure of boreal and arctic endophytes from three major plant lineages. Mol. Phylogenet. Evol. 2007, 42, 543-555. [CrossRef] [PubMed]

43. Debbab, A.; Aly, A.H.; Edrada-Ebel, R.; Wray, V.; Müller, W.E.; Totzke, F.; Zirrgiebel, U.; Schächtele, C.; Kubbutat, M.H.; Lin, W.H. Bioactive metabolites from the endophytic fungus Stemphylium globuliferum isolated from Mentha pulegium. J. Nat. Prod. 2009, 72, 626-631. [CrossRef] [PubMed]

44. Xu, J.; Ebada, S.S.; Proksch, P. Pestalotiopsis a highly creative genus: Chemistry and bioactivity of secondary metabolites. Fungal Divers. 2010, 44, 15-31. [CrossRef]

45. Poczai, P.; Hyvönen, J. Nuclear ribosomal spacer region in plant phylogenetics: Problems and prospects. Mol. Biol. Rep. 2010, 37, 1897-1912. [CrossRef] [PubMed]

46. Brader, G.; Compant, S.; Vescio, K.; Mitter, B.; Trognitz, F.; Ma, LJ.; Sessitsch, A. Ecology and Genomic Insights into Plant-Pathogenic and Plant-Nonpathogenic Endophytes. Ann. Rev. Phytopathol. 2017, 55, 61-83. [CrossRef] [PubMed]

47. Barbosa, M.V.; Pereira, E.A.; Cury, J.C.; Carneiro, M.A.C. Occurrence of arbuscular mycorrhizal fungi on King George Island, South Shetland Island, Antarctica. Anais Acad. Bras. Ciênc. 2017, 8, 1737-1743. [CrossRef] [PubMed]

48. Putzke, J.; Pereira, A.B. Phaeosphaeria deschampsii (Ascomycota): A new parasite species of Deschampsia antarctica (Poaceae) described to Antarctica. Ann. Braz. Acad. Sci. 2016, 88, 1967-1969. [CrossRef] [PubMed]

49. Zucconi, L.; Pagano, S.; Fenice, M.; Selbmann, L.; Tosi, S.; Onofri, S. Growth temperature preferences of fungal strains from Victoria Land, Antarctica. Polar Biol. 1996, 16, 53-61. [CrossRef]

50. Tosi, S.; Casado, B.; Gerdol, R.; Caretta, G. Fungi isolated from Antarctic mosses. Polar Biol. 2002, 25, $262-268$.

(C) 2018 by the authors. Licensee MDPI, Basel, Switzerland. This article is an open access article distributed under the terms and conditions of the Creative Commons Attribution (CC BY) license (http:// creativecommons.org/licenses/by/4.0/). 